\title{
Deskripsi Keterampilan Berpikir Tingkat Tinggi (HOTS) Peserta Didik Menggunakan Model Guided Inquiry Pada Materi Hukum Dasar Kimia
}

\section{Description of Higher Order Thinking Skills (HOTS) of Students Using Guided Inquiry Models on Basic Law of Chemistry}

\author{
Y Mairoza $^{1}$ and Z Fitriza ${ }^{1^{*}}$ \\ 1 Pendidikan Kimia, Universitas Negeri Padang, \\ Jl. Prof. Dr. Hamka, Air Tawar Barat, Padang Utara, Sumatera Barat, Indonesia. 25171 \\ *zonaliafitriza@gmail.com
}

\section{ARTICLE INFO \\ Received on: \\ 22 August 2020 \\ Revised till: \\ 15 December 2020}

Accepted on:

30 December 2020

Publisher version published on:

28 February 2021

\begin{abstract}
This study aims to describe the HOTS of students use a guided inquiry model on the basic laws of chemistry. This research is a library research, and the type of library research used is semi-systematic. Sources are secondary data from reputable scientific journals. The documentation method was used in collecting data and data analysis techniques used the Miles and Huberman method. Data analysis activities in the miles and huberman method consist of data reduction, data presentation, and conclusions. Based on the results of the journal review, it is concluded that the guided inquiry model can increase the HOTS of students and can be seen in the exploration, concept formation, application and closing stages of how to use the guided inquiry model in bringing out students' HOTS on basic law of chemistry.
\end{abstract}

\section{KEYWORDS}

Basic Law of Chemistry, Guided Inquiry Models, Higher Order Thinking Skills

\section{ABSTRAK}

Tujuan penelitian ini untuk mendeskripsikan HOTS peserta didik menggunakan model guided inquiry pada materi hukum dasar kimia. Penelitian ini merupakan penelitian kepustakaan, dan jenis penelitian kepustakaan yang digunakan adalah semi-sistematis. Sumber berupa data sekunder yang berasal dari jurnal ilmiah bereputasi. Metode dokumentasi digunakan dalam mengumpulkan data dan teknik analisis data menggunakan metode Miles dan Huberman. Kegiatan analisis data pada metode Miles dan Huberman terdiri dari reduksi data, penyajian data, dan kesimpulan. Berdasarkan hasil tinjauan jurnal didapatkan kesimpulan bahwa model Guided Inquiry dapat meningkatkan HOTS peserta didik serta dapat dilihat pada tahap eksplorasi, pembentukan konsep, aplikasi dan penutup bagaimana penggunaan model Guided Inquiry dalam memunculkan HOTS peserta didik pada materi hukum dasar kimia.

KATA KUNCI

Hukum Dasar Kimia, Model Guided Inquiry, HOTS 


\section{PENDAHULUAN}

Kurikulum 2013 menuntut peserta didik berpartisipasi aktif dalam proses belajar serta memiliki keterampilan HOTS. Tujuan utama pendidikan di abad ke-21 adalah keterampilan HOTS yang sangat penting untuk membina peserta didik agar mampu menghadapi tantangan global ${ }^{[1]}$. Tuntutan era globalisasi yang semakin meningkat harus melatih peserta didik yang berkualitas, memiliki sifat ilmiah, nilai, sikap dan keterampilan HOTS, sehingga muncul peserta didik yang berpikir kritis, kreatif, mengambil keputusan dan memecahkan masalah.

Keterampilan HOTS adalah proses berpikir peserta didik pada tingkat kognitif yang lebih tinggi, tidak hanya menghafal dan menyatakan kembali informasi yang diketahui. Keterampilan HOTS bertujuan untuk meningkatkan keterampilan berpikir tingkat peserta didik, terutama yang terkait dengan kemampuan menghubungkan, memanipulasi, dan mentransformasi pengetahuan dari pengalaman yang dimiliki untuk berpikir kritis dan kreatif untuk dapat membuat keputusan dan memecahkan masalah yang kompleks ${ }^{[2]}$.

Taksonomi Bloom yang direvisi oleh Anderson \& Krathwohl adalah dasar dari berpikir tingkat tinggi dan memiliki urutan tingkatan berpikir dari tingkat rendah ke tingkat tinggi ${ }^{[3]}$. Keterampilan HOTS meliputi kemampuan kognitif analisis (C4), evaluasi (C5) dan kreativitas (C6).

Kegiatan pembelajaran yang dapat mengembangkan keterampilan berpikir adalah merumuskan masalah, membuat hipotesis, kegiatan presentasi yang memfasilitasi peserta didik untuk melakukan kegiatan tanya jawab, dan mengevaluasi proses mencari solusi dari permasalahan ${ }^{[4]}$. Hal ini mirip dengan ranah keterampilan HOTS yaitu: analisis, evaluasi dan kreativitas.

Kimia adalah salah satu cabang Ilmu Pengetahuan Alam (IPA) yang melibatkan karakteristik zat, struktur zat, perubahan zat, dan hukum serta prinsip yang menjelaskan perubahan zat $^{[5]}$. Sebagian besar siswa SMA menganggap kimia itu sulit, karena sebagian besar ilmu kimia bersifat abstrak, melibatkan persamaan reaksi serta ilmu kimia tidak sekadar memecahkan soal ${ }^{[6]}$.

Hukum dasar kimia merupakan materi pokok kimia pada kurikulum 2013 yang dipelajari di SMA/ MA kelas X semester genap. Hukum dasar kimia bersifat konkret dan abstrak juga sering dikaitkan dengan kehidupan sehari- hari. Oleh karena itu, diperlukan pemahaman konsep yang tinggi dan kemampuan berpikir yang baik ${ }^{[7]}$.

Penulis memperoleh informasi dari hasil tanya jawab dengan guru kimia SMA N 7 Padang dan SMA Pembangunan Laboratorium UNP bahwa sebagian besar siswa kelas X MIPA mendapatkan kategori tidak tuntas pada materi hukum dasar kimia karena peserta didik hanya mampu menghafal sehingga ketika diberikan suatu masalah siswa kebingungan untuk memecahkan masalah tersebut secara kompleks. Oleh karena itu, diperlukan model pembelajaran yang dapat mendukung peserta didik dalam meningkatkan keterampilan HOTS melalui penerapan model pembelajaran Guided Inquiry.

Model Guided Inquiry dapat disinergikan dengan kegiatan HOTS untuk mengembangkan kemampuan berpikir kritis, logis, sistematis dan analitis sehingga peserta didik dapat menemukan konsep dengan mandiri. Siklus pembelajaran model guided inquiry meliputi 5 tahap yaitu orientasi, eksplorasi, pembentukan konsep, aplikasi dan penutup ${ }^{[8]}$. Pada tahap eksplorasi dan pembentukan konsep peserta didik membutuhkan keterampilan HOTS karena terdapat kegiatan melakukan observasi/pengamatan, mengajukan hipotesis, mengumpulkan dan menganalisis data dan menarik kesimpulan ${ }^{[4]}$.

Berdasarkan uraian di atas, maka tujuan penelitian ini adalah menggunakan model guided inquiry pada materi hukum dasar kimia untuk mendeskripsikan keterampilan HOTS peserta didik. Kemunculan keterampilan HOTS peserta didik dapat diukur pada tingkat berpikir analisis (C4), evaluasi (C5) dan kreativitas(C6) ${ }^{[9]}$.

Penelitian ini dapat menjadi sumber informasi bagi guru dan khalayak tentang keterampilan HOTS peserta didik menggunakan model guided inquiry pada materi hukum dasar kimia. Penelitian ini juga diharapkan dapat menjadi bahan pertimbangan untuk menggunakan model guided inquiry dan memberikan referensi untuk penelitian selanjutnya.

\section{METODE}

Jenis penelitian yang diterapkan adalah penelitian kepustakaan yaitu penelitian yang dilakukan dengan cara mengumpulkan data pustaka, mencatat dan mengolah bahan dari literatur- literatur tanpa melakukan riset lapangan ${ }^{[10]}$. Penelitian kepustakaan dilakukan dengan menerapkan pendekatan semi-sistematis yang bertujuan untuk mengidentifikasi dan memahami penelitian yang relevan terkait dengan topik penelitian ${ }^{[1]}$.

Data yang digunakan adalah data sekunder. Data sekunder merupakan data yang diperoleh bukan dari pengamatan langsung dengan menerapkan metode dokumentasi. Sumber data sekunder dalam penelitian ini berupa jurnal bereputasi dan didukung dengan jurnal yang belum bereputasi. Jurnal-jurnal tersebut diambil dari situs database jurnal seperti https://www.tandfonline.com/, https:// www.elsevier.com/en-xs, https://iopscience.iop.org/, https://onlinelibrary.wiley.com/ dan https://scholar. google.com/.

Data sekunder yang didapatkan selanjutnya dianalisis menggunakan teknik analisa Miles \& Huberman. Analisis data meliputi tiga kegiatan, yaitu reduksi data, penyajian data dan penarikan kesimpulan. Data tersebut dikelompokkan menjadi tiga bagian yaitu keterampilan HOTS, model guided inquiry, dan hukum dasar kimia. Data yang tidak terkait dengan masalah penelitian dibuang. 
Penelitian ini dilakukan melalui tahapan sebagai berikut: 1) mendasari review, pada tahap ini dilakukan pemilihan topik yang relevan dengan penelitian serta merumuskan tujuan dan merumuskan masalah yang akan dibahas, 2) melakukan review, tahap ini dilakukan dengan cara membaca abstrak artikel yang sesuai dengan topik penelitian. Jika abstrak sudah sesuai dengan topik penelitian dilanjutkan dengan membaca isi artikel, 3) analisis, analisis dilakukan sesuai dengan tujuan dan rumusan masalah penelitian. Data yang dapat diambil berupa informasi deskriptif, seperti pengarang, tahun terbit, topik, jenis penelitian dan hasil temuan, 4) menulis review, menulis review dilakukan sesuai dengan topik penelitian ${ }^{[11]}$.

\section{HASIL DAN DISKUSI}

\subsection{Hasil Penelitian}

Hasil analisis literatur diperoleh dengan menggabungkan empatbelas jurnal dengan delapan jurnal bereputasi dan enam jurnal yang belum bereputasi lalu mengelompokkan bagian-bagian yang berkaitan dengan tujuan penelitian yaitu keterampilan HOTS, model guided inquiry dan hukum dasar kimia. Model guided Inquiry diambil dari jurnal enam jurnal, dari keenam jurnal tersebut diambil tahap-tahap belajar guided inquiry $\left.{ }^{8,12-13}\right]$. Jurnal yang berkaitan dengan keterampilan HOTS terdiri dari empat jurnal[ $\left.{ }^{3,16-18}\right]$. Kegiatan pembelajaran hukum dasar kimia menggunakan model guided inquiry terdiri dari dua jurnal ${ }^{[19-20]}$. Model guided inquiry dalam memunculkan keterampilan HOTS terdiri dari dua jurnal[ ${ }^{[9,21]}$.

Hasil peningkatan HOTS peserta didik untuk setiap level kognitif menggunakan pembelajaran model inkuiri terbimbing terangkum pada Gambar 1. Peningkatan skor N-Gain keseluruhan peserta didik kelas eksperimen lebih tinggi daripada kelas kontrol. Hal ini menunjukkan bahwa model guided inquiry dapat meningkatkan HOTS siswa untuk setiap level kognitifnya.

Hasil peningkatan HOTS untuk setiap indikator HOTS dengan menerapkan model guided inquiry seperti terlihat pada Gambar 2. Berdasarkan Gambar 2. Dapat terlihat nilai $\mathrm{N}$-gain dari indikator HOTS adalah analisis (C4), evaluasi (C5) dan kreativitas (C6) lebih tinggi di kelas eksperimen daripada kelas kontrol karena menerapkan model guided inquiry.

\section{Nilai N-Gain Peserta Didik untuk Setiap Indikator}

Indikator Analisis (C4)

\section{0,769}

\section{0,604}

0,646

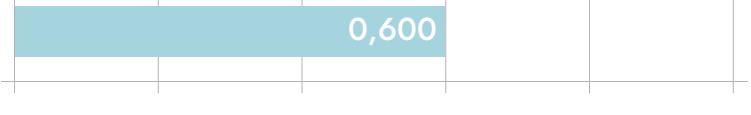
0,0
0,2
0,4
0,6
0,8
1,0

Indikator Evaluasi (C5)

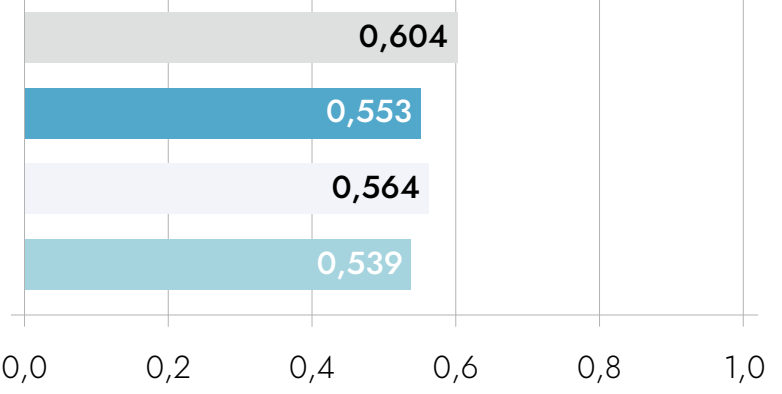

Indikator Kreativitas (C6)

\section{0,705}

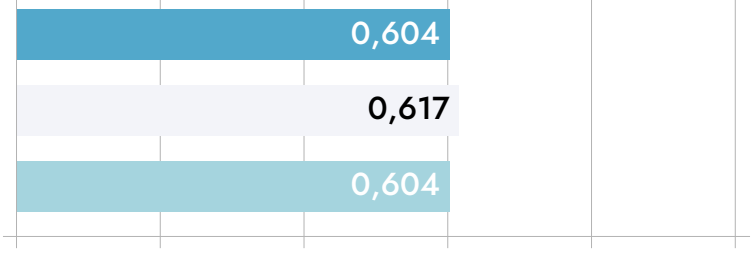
0,0
0,2
0,4
$0,6 \quad 0,8$
1,0

Legenda
Kelas Eksperimen 1
Kelas Kontrol 1
Kelas Eksperimen 2
Kelas Kontrol 2

Gambar 2. N-Gain HOTS peserta didik untuk setiap Indikator ${ }^{[21]}$.

\subsection{Pembahasan}

\subsubsection{HOTS dalam Model Pembelajaran Inkuiri Terbimbing}

Hasil tinjauan dari beberapa jurnal didapatkan bahwa HOTS sangat penting dikuasai peserta didik karena beberapa alasan yaitu: 1) HOTS dapat mengembangkan keterampilan berpikir

\section{Nilai Rata-Rata dari Aspek Kognitif Siswa}
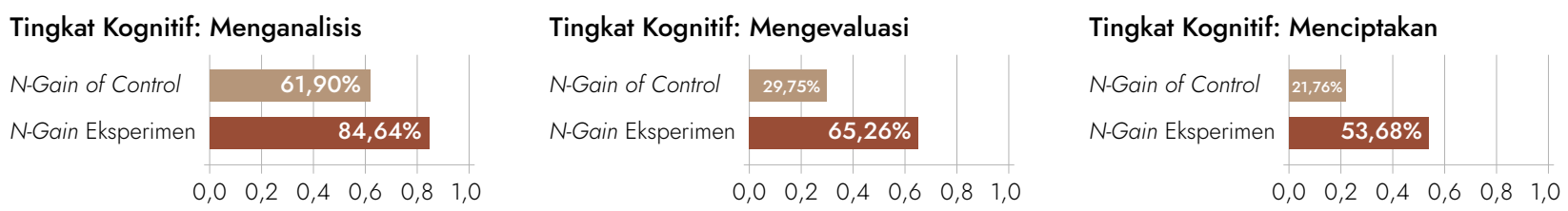

Gambar 1. Perbandingan HOTS untuk Setiap Level Kognitif Kelas Sampe ${ }^{[9]}$. 
dan minat peserta didik, 2) HOTS membantu proses pengambilan keputusan, 3) HOTS membantu peserta didik dalam memberikan pendapat yang kuat, 4) HOTS membantu peserta didik berpikir secara luas dari berbagai sudut pandang agar dapat merespon masalah dengan baik, 5) HOTS membantu peserta didik menghasilkan ide dalam menyelesaikan tugas, 6) membuat peserta didik lebih aktif dan berpartisipasi dalam diskusi ${ }^{[16,18]}$.

Taksonomi Bloom yang direvisi dalam mengungkapkan HOTS peserta didik dalam ranah kognitif C4 - C6 yaitu analisis (C4), evaluasi (C5) dan kreativitas (C6) ${ }^{[9]}$. Ada tiga proses kognitif dalam analisis yaitu membedakan, mengorganisir dan menguraikan, kemudian dua proses kognitif dalam mengevaluasi yaitu memeriksa dan mengkritik dan tiga proses kognitif dalam mencipta yaitu membuat, merencanakan dan memproduksi ${ }^{[17]}$.

Hasil tinjauan jurnal ${ }^{[17]}$ pada ranah menganalisis peserta didik akan menghadapi fenomena agar dapat merumuskan masalah dan mengajukan hipotesis. Ranah mengevaluasi, siswa akan dihadapkan dengan pertanyaan-pertanyaan yang dipecahkan dalam diskusi kelas dan pada ranah kreasi, peserta didik secara mandiri merancang percobaan atau meracang sebuah karya. Akan tetapi, tingkat setiap kecerdasan setiap peserta didik berbeda-beda dan bisa berdampak pada pemilihan strategi, teknik dan model pembelajaran.

Hasil tinjauan jurnal ${ }^{[14,21]}$ didapatkan bahwa rata-rata capaian HOTS peserta didik meningkat melalui penerapan model guided inquiry seperti yang tercantum pada Gambar 1 dan Gambar 2. Hal ini terjadi karena melalui pembelajaran guided inquiry, guru mengajak peserta didik untuk terlibat aktif dalam proses pembelajaran. Sehingga, peserta didik akan aktif berpikir mengenai masalah, melakukan percobaan untuk menemukan jawaban, menganalisis dan menafsirkan data serta mendiskusikan hasilnya untuk menarik kesimpulan.

Hasil tinjauan jurnal ${ }^{[9]}$ didapatkan hubungan HOTS dengan model inkuiri terbimbing: 1) mengidentifikasi masalah, pada tahap ini ketika disajikan sebuah fenomena peserta didik diminta mengajukan pertanyaan dan merumuskan masalah sehingga belum terdapat kegiatan HOTS, 2) menyusun hipotesis, pada tahap ini peserta didik menyusun hipotesis yang berkaitan dengan masalah dan memutuskan hipotesis mana yang akan digunakan sebagai bahan penelitian sehingga sudah terdapat kegiatan HOTS pada aspek menganalisis, 3) investigasi dan pengumpulan data, pada tahap ini peserta didik menentukan dan melakukan langkah-langkah percobaan dan mengumpulkan data sehingga terdapat kegiatan HOTS pada aspek menganalisis, 4) analisis data, pada tahap ini peserta didik mengolah data yang terkumpul dan menguji hipotesis yang telah dirumuskan, 5) refleksi atau kesimpulan, pada tahap ini peserta didik memutuskan, memprediksi, menafsirkan dan menjelaskan dengan membuat kesimpulan berdasarkan analisis data sehingga terdapat kegiatan HOTS pada aspek mencipta.

\subsubsection{Deskripsi HOTS dalam Model Pembelajaran Inkuiri Terbimbing pada Materi Hukum Dasar Kimia}

Hasil tinjauan dari beberapa jurnal terdapat 3 jurnal mengenai tahap model guided inquiry. Menurut pendapat yang pertama model guided inquiry terdiri dari orientasi, eksplorasi, pembentukan konsep, aplikasi dan penutup ${ }^{[8]}$. Tahapan model inkuiri terbimbing yang kedua terdiri dari inisiasi, seleksi, eksplorasi, formulasi, koleksi dan presentasi ${ }^{[12]}$ dan tahapan model inkuiri terbimbing yang ketiga terdiri dari orientasi, konseptualisasi, investigasi, kesimpulan dan diskusi ${ }^{[14]}$. Dari ketiga tahapan model guided inquiry dapat diambil kesamaan dan kesimpulan yaitu tahapan model inkuiri terbimbing dimulai dari orientasi, eksplorasi, pembentukan konsep, aplikasi dan penutup .

Hasil tinjauan jurnal mengenai kegiatan pembelajaran materi hukum dasar kimia menggunakan guided inquiry di analisis dari jurnal ${ }^{[19-20]}$. Tahapan model guided inquiry pada hukum dasar kimia yang telah didapatkan kesimpulannya kemudian dianalisis untuk dikaitkan dengan HOTS dan dideskripsikan kegiatan yang dilakukan dengan memperhatikan proses kognitif yang muncul.

Berikut kemunculan HOTS menggunakan model guided inquiry pada materi hukum dasar kimia dapat dilihat pada setiap tahapannya.

\subsubsection{Orientasi}

Tahap orientasi siswa dipersiapkan untuk belajar dengan memberikan motivasi untuk merangsang minat dan keingintahuan dengan mengajukan masalah untuk dipecahkan atau pertanyaan untuk diselidiki. Sesuai dengan kegiatan pembelajaran pada materi hukum dasar kimia yang dilaksanakan pada tahap ini dimulai dengan mengajukan masalah seperti guru menyajikan fenomena perkaratan menggunakan dua gambar besi berkarat dan yang tidak berkarat. Peserta didik diminta untuk merumuskan masalah dari fenomena tersebut. Contohnya “Mengapa besi bisa mengalami perkaratan ketika berada di sistem terbuka dibandingkan pada sistem tertutup"?. Maka tidak memungkinkan untuk muncul HOTS karena peserta didik belum dituntut menjawab pada tahap ini dan jawaban itu akan didapatkan pada tahap berikutnya.

\subsubsection{Eksplorasi}

Tahap eksplorasi peserta didik berkesempatan untuk mengamati, merancang dan melakukan percobaan, mengumpulkan, menganalisis data, mengusulkan, menanyakan, merumuskan dan membuat hipotesis. Sesuai dengan kegiatan pembelajaran pada materi hukum dasar kimia yaitu merumuskan hipotesis, contohnya adalah besi akan cepat mengalami perkaratan pada sistem terbuka karena terkontaminasi udara dibandingkan dengan besi pada sistem tertutup yang tidak terkontaminasi udara. Dalam kegiatan ini saat peserta didik diminta untuk merumuskan hipotesis maka akan muncul HOTS pada level berpikir kreativitas (C6). 
Kategori pada kreativitas terdiri dari membuat, merencanakan dan memproduksi yang mana merumuskan hipotesis ini termasuk ke dalam proses kognitif membuat.

\subsubsection{Pembentukan Konsep}

Tahap pembentukan konsep dimana konsep diciptakan, dikenalkan dan dibentuk sebagai hasil dari eksplorasi. Proses ini disusun dengan menyediakan pertanyaan yang menuntun peserta didik untuk berpikir kritis dan analitis pada saat eksplorasi. Peserta didik secara berkelompok dapat menemukan hubungan antar variabel sehingga dapat menarik kesimpulan dan membuktikan hipotesis. Sesuai dengan kegiatan pembelajaran pada materi hukum dasar kimia yaitu melakukan percobaan, mengambil data hasil percobaan dan menganalisis data hasil percobaan untuk menjawab hipotesis. Dengan demikian, pada tahap ini peserta didik sudah memiliki keterampilan HOTS pada level berpikir evaluasi (C5) dengan kategori memeriksa dan mengkritik karena peserta didik dituntut untuk menganalisis data untuk menjawab hipotesis dan menarik kesimpulan. Tentunya sebelum peserta didik sampai pada level berpikir mengevaluasi (C5) terlebih dahulu peserta didik telah melewati level berpikir menganalisis (C4).

\subsubsection{Aplikasi}

Tahap aplikasi konsep diidentifikasi dan dipahami, selanjutnya konsep tersebut akan diperkuat dan diperluas dengan mengaplikasikan dalam latihan. Sesuai dengan kegiatan pembelajaran pada materi hukum dasar kimia yaitu kegiatan pembentukan konsep pada materi hukum dasar kimia adalah menuntun peserta didik untuk menjawab soal- soal pada lembar kerja. Soal-soal yang terdapat di dalam lembar kerja tentunya bervariasi memungkinkan dari level berpikir C1- C6, maka kemungkinan akan muncul HOTS pada saat siswa menjawab soal C4 - C6.

\subsubsection{Penutup}

Tahap terakhir adalah penutup dimana pada tahap ini peserta didik menarik kesimpulan berdasarkan hasil percobaan yang diperoleh, contohnya peserta didik dapat menyimpulkan bahwa "dalam sistem tertutup massa zat sebelum dan sesudah reaksi adalah sama. Hal ini sesuai dengan hukum kekekalan massa (Lavoisier)”. Kemudian peserta didik mempresentasikan, mengomunikasikan temuan dan kesimpulan kepada guru dan peserta didik lain untuk mengomunikasikan hasil penyelidikannya. Dari hasil kesimpulan, kegiatan penutup pada materi hukum dasar kimia menggunakan model guided inquiry adalah membuat kesimpulan akhir yang mana pada kegiatan ini akan muncul HOTS pada level berpikir evaluasi (C5) serta menilai dan mengevaluasi apakah kesimpulan sudah sesuai atau belum.

\section{SIMPULAN}

Berdasarkan tinjauan daribeberapa jurnal dapat disimpulkan HOTS peserta didik meningkat dengan menerapkan model guided inquiry. Selanjutnya, kemunculan HOTS peserta didik pada hukum dasar kimia menggunakan model guided inquiry dapat lihat pada tahap eksplorasi yaitu muncul level berpikir mencipta (C6) kategori membuat karena peserta didik merumuskan hipotesis. Tahap pembentukan konsep muncul level berpikir mengevaluasi (C5) dengan kategori memeriksa dan mengkritik karena peserta didik melakukan percobaan, mengambil data hasil percobaan dan menganalisis data hasil percobaan untuk menjawab hipotesis. Tahap aplikasi muncul keterampilan HOTS ketika peserta didik menjawab soal- soal pada lembar kerja. Soalsoal yang terdapat di dalam lembar kerja tentunya bervariasi memungkinkan dari level berpikir C1C6, maka kemungkinan akan muncul HOTS pada saat peserta didik menjawab soal C4 - C6. Tahap penutup muncul level berpikir mengevaluasi (C5) karena peserta didik membuat kesimpulan akhir.

\section{REFERENSI}

1. Muspawi M, Suratno, Ridwan. Upaya Peningkatan Higher Order Thinking Skills (HOTS) Siswa Melalui Penerapan Model Inquiri di SMA Negeri 9 Tanjung Jabung Timur. J Ilm Univ Batanghari Jambi. 2019;19(2):208-14.

2. Rofiah E. Penyusunan Instrumen tes kemampuan berpikir tingkat tinggi fisika pada siswa SMP. 2013;

3. Anderson LW, Krathwohl DR. A Taxonomy for learning, teaching, and assesing; a revision of bloom's taxonomy of educational objectives. New York: Addison Wesley Longman; 2001.

4. Khofifatin, Yonata B. Ketuntasan Belajar Siswa Dalam Berpikir Tingkat Tinggi Pada Materi Pokok Larutan Asam Basa Kelas Xi Sma Negeri 1 Gedangan Sidoarjo Dengan Menerapkan Model Pembelajaran Inkuiri (The Mastery Of Student Learning In Higher Order Thinking Skill On Main Subj. Unesa J Chem Educ. 2013;2(2).

5. Effendy. Molekul, Struktur dan Sifat-Sifatnya. Malang: Indonesia Academic Publishing; 2017.91 p.

6. Rumansyah. Penerapan Metode Latihan Berstruktur dalam Meningkatkan Pemahaman Siswa Terhadap Konsep Persamaan Reaksi Kimia. Jurnal Pendidikan Nasional dan Kebudayaan. 2002.

7. Norjana R, Santosa, Joharmawan R. Identifikasi Tingkat Pemahaman Konsep Hukum-Hukum Dasar Kimia Dan Penerapannya Dalam Stoikiometri Pada Siswa Kelas X IPA di MAN 3 Malang. J-Pek (Jurnal Pembelajaran Kim. 2016;1(2):42-9.

8. Hanson DM. Designing Process-Oriented Guided-Inquiry Activities. Fac Guid Compr Tool Improv Fac Performance 2nd Ed Pacific Crest. 2005; 
9. Risna R, Hasan M, Supriatno S. Penerapan Model Inkuiri Terbimbing Berorientasi Green Chemistry untuk Meningkatkan Hasil Belajar Siswa pada Materi Larutan Penyangga. Jurnal IPA dan Pembelajaran IPA. 2019;3(2):106-118.

10. Mestika, Zed. Metode Penelitian Kepustakaan. Jakarta: Yayasan Bogor Indonesia. 2004;

11. Snyder H. Literature Review As A Research Methodology: An Overview And Guidelines. J Bus Res. 2019;104:333-9.

12. Kuhlthau CC. Guided Inquiry: School Libraries in the 21st Century. Sch Libr Worldw. 2010;16(1):17-28.

13. Pedaste M, Mäeots M, Siiman LA, De Jong T, Van Riesen SAN, Kamp ET, et al. Phases of Inquiry-Based Learning: Definitions and the Inquiry Cycle. Educ Res Rev. 2015;14:47-61.

14. Douglas EP, Chiu C-C. Process-Oriented Guided Inquiry Learning In Engineering. Procedia-Social Behav Sci. 2012;56:253-7.

15. Andalan M, Fadiawati N, Kadaritna N. Efektivitas Pembelajaran Inkuiri Terbimbing Pada Materi Koloid Dalam Meningkatkan Keterampilan Berpikir Lancar. J Pendidik Dan Pembelajaran Kim. 2013;2(3).

16. Lestari ZW. The Importance of Higher Order Thinking Skills for Senior High School's Students. In: International Conference On Education And Science 2017 Proceeding. 2017. P. 1065-9.

17. Anggraini NP, Budiyono, Pratiwi H. Analysis of Higher Order Thinking Skills Students at Junior High School In Surakarta. In: Journal Of Physics: Conference Series. Iop Publishing; 2019. P. 12077.

18. Heong YM, Yunos JM, Othman W, Hassan R, Kiong TT, Mohamad MM. The Needs Analysis of Learning Higher Order Thinking Skills for Generating Ideas. Procedia-Social Behav Sci. 2012;59:197-203.

19. Laliyo LAR, Kau M, Kilo JL, Kilo AL. Kemampuan Siswa Memecahkan Masalah Hukum-Hukum Dasar Kimia Melalui Pembelajaran Inkuiri Terbimbing. Ar-Razi J Ilm. 2020;8(1).

20. Ermalinda Y, Rudibyani RB, Sofya E. Analisis Kemampuan Menyimpulkan Pada Materi Hukum-Hukum Dasar Kimia Dengan Inkuiri Terbimbing. J Pendidik Dan Pembelajaran Kim. 2014;3(3).

21. Mawardi, Rusiani JAF, Yani FH. Effectiveness of Student Worksheets Based Guided Inquiry On Acid Base Material To Improve Students Higher Order Thinking Skill (HOTS). J Phys Conf Ser. 2020;1481(1). 